\title{
COOP/WONCA Charts as a Screen for Mental Disorders in Primary Care
}

Joao Mazzoncini de AzevedoMarques, $M D, P b D^{1}$

Antonio Waldo Zuardi, MD, $\mathrm{PbD}^{2}$

'University Hospital, Medical School of Ribeirao Preto, University of Sao Paulo, Sao Paulo, Brazil

${ }^{2}$ Department of Neurosciences and Behavior, Medical School of Ribeirao Preto, University of Sao Paulo, Sao Paulo, Brazil

Conflicts of interest: authors report none.

\section{CORRESPONDING AUTHOR}

Joao Mazzoncini de Azevedo-Marques, $\mathrm{MD}, \mathrm{PhD}$

Hospital das Clínicas da Faculdade de Medicina de Ribeirao

Preto da Universidade de São Paulo

Campus Universitário

Monte Alegre, Ribeirao Preto

Estado de São Paulo, Brasil 14015-130

jmaq@uol.com.br

\begin{abstract}
PURPOSE Most people with mental disorders receive treatment in primary care. The charts developed by the Dartmouth Primary Care Cooperative Research Network (COOP) and the World Organization of National Colleges, Academies, and Academic Associations of General Practitioners/Family Physicians (WONCA) have not yet been evaluated as a screen for these disorders, using a structured psychiatric interview by an expert or considering diagnoses other than depression. We evaluated the validity and feasibility of the COOP/WONCA Charts as a mental disorders screen by comparing them both with other questionnaires previously validated and with the assessment of a mental health specialist using a structured diagnostic interview.
\end{abstract}

METHODS We trained community health workers and nurse assistants working in a collaborative mental health care model to administer the COOP/WONCA Charts, the 20-item Self-Reporting Questionnaire (SRQ-20), and the World Health Organization-Five Well-Being Index (WHO-5) to 120 primary care patients. A psychiatrist blinded to the patients' results on these questionnaires administered the SCID, or Structured Clinical Interview for the DSM-IV (Diagnostic and Statistical Manual of Mental Disorders, Fourth Edition).

RESULTS The area under the receiver operating characteristic curve was at least 0.80 for single items, a 3 -item combination, and the total score of the COOP/ WONCA Charts, as well as for the SRQ-20 and the WHO-5, for screening both for all mental disorders and for depressive disorders. The accuracy, sensitivity, specificity, and positive and negative predictive values of these measures ranged between 0.77 and 0.92. Community health workers and nurse assistants rated the understandability, ease of use, and clinical relevance of all 3 questionnaires as satisfactory.

CONCLUSIONS One-time assessment of patients with the COOP/WONCA Charts is a valid and feasible option for screening for mental disorders by primary care teams.

Ann Fam Med 2011;9:359-365. doi:10.1370/afm.1267.

\section{INTRODUCTION}

$\mathrm{E}$ pidemiologic studies of the adult population have found the prevalence of mental disorders is as high as $20 \%$ in 1 year and $40 \%$ in a lifetime. ${ }^{1-3}$ Disabilities, decreased quality of life, and the economic consequences associated with the presence of common mental disorders are similar to those associated with common nonpsychiatric diseases. ${ }^{1,4,5}$ Moreover, the presence of mental disorders increases the risk and worsens the prognosis of these nonpsychiatric diseases. ${ }^{6,7}$ Many people with mental disorders receive treatment in primary health care facilities; however, primary care teams often detect, correctly diagnose, and adequately treat less than $50 \%$ of mental disorder cases ${ }^{8-10}$ Increasing evidence shows that there is a better chance of achieving good mental health outcomes when these teams work within collaborative care models that include mental health specialists who perform consultation/liaison activities and provide specialized care in primary care facilities. ${ }^{11-15}$ 
In primary care services with these organizational characteristics, questionnaires can be used to facilitate screening for mental disorders. ${ }^{16-18}$ Examples of such questionnaires include the 20-item Self-Reporting Questionnaire (SRQ-20), ${ }_{1}^{19}$ the General Health Questionnaire, ${ }^{20}$ the World Health Organization-Five Well-Being Index (WHO-5), ${ }^{21}$ and the first phase of interviews of the Symptom-Driven Diagnostic System for Primary Care ${ }^{22}$ and Primary Care Evaluation of Mental Disorders. ${ }^{17}$ The Dartmouth Primary Care Cooperative Research Network (COOP) and the World Organization of National Colleges, Academies, and Academic Associations of General Practitioners/ Family Physicians (WONCA) developed a 6-item questionnaire or set of charts to evaluate the physical, emotional, and social well-being of a person subjectively, called the COOP/WONCA Charts. ${ }^{23}$ These charts include a specific item to assess mental health (Feelings), as well as items of Physical Fitness, Daily Activities, Social Activities, Change in Health Status, and Overall Health. The WHO-5, which was originally developed to assess well-being in patients with chronic conditions, is an efficient screen for depressive and anxiety disorders. ${ }^{24}$ Accordingly, it is possible that the COOP/WONCA Charts, in addition to their original objectives, could also identify patients who are mentally ill. To date, previous studies showed significant concordance only between the COOP/WONCA Charts and a depression diagnosis made by general practitioners or rating scales of depressive symptoms. ${ }^{25-27}$

In this study, we compared, in a collaborative mental health care model, the validity and feasibility of the COOP/WONCA Charts, the SRQ-20, and the WHO-5 administered by Brazilian primary health care teams as screening tools, for mental disorders in general and also for depressive and anxiety disorders in specific, using the SCID, or Structured Clinical Interview for the DSM-IV (Diagnostic and Statistical Manual of Mental Disorders, Fourth Edition), clinical version, ${ }^{28,29}$ to definitively establish the presence or absence of these disorders.

\section{METHODS}

\section{Context of the Study}

Since 1999, primary health care teams linked to the Ribeirao Preto Medical School work according to the Brazilian Family Health Program (FHP) ${ }^{30-33}$ and have access to mental health specialists who perform weekly consultation/liaison activities and provide specialized care in FHP facilities. Additionally, family physicians and primary care nurses are trained in mental health in academic seminars during a period of 1 year (40 seminars in total, 2 hours each), with goals of integrating mental health in a patient-centered/biopsychosocial approach $^{34}$ and enabling these professionals to provide continuous support in this area for community health workers and nurse assistants.

At the time of this study in 2003, there were 4 FHP teams, covering a population of approximately 15,000 inhabitants. Each team had 4 community health workers, 2 nurse assistants, 1 nurse, 1 senior family physician, and 2 or 3 family medicine residents.

\section{Questionnaires and Psychiatric Interview}

The SRQ-20 was developed by WHO in the 1970s for a multinational study on mental disorders in primary care. It consists of 20 questions with possible answers of only yes or no ${ }^{19}$ and can be self-administered or administered by an interviewer. It is widely used in studies in developing countries to screen for nonpsychotic mental disorders in primary care, and the Brazilian version has been validated. ${ }^{35}$ Higher scores indicate more symptoms.

The WHO-5 is a questionnaire that measures wellness ${ }^{21}$ and can discriminate between older adults with and without mental disorders. ${ }^{24}$ There are 2 versions, each having 5 items; Version 1 detects anxiety and depression, while Version 2 detects only depression. ${ }^{36}$ On the basis of these data and considering the importance of detecting various mental disorders in primary care, we translated the first version for this study. Higher scores indicate greater wellness.

The COOP/WONCA Charts were developed in the late 1980s and early 1990s under the auspices of WONCA, with the aim of subjectively evaluating an individual's functional status, defined as assessing his or her physical, emotional, and social well-being. These charts measure functioning in 6 aforementioned domains. Each chart consists of a single question referring to the preceding 2 weeks and has 5 possible answers, illustrated by a simple picture. This tool has been translated into multiple languages and validated in several countries. We used the Portuguese version, with minor modifications for use in Brazil. ${ }^{23,37,38}$ Higher scores indicate a worse functional status.

The psychiatric diagnoses that we used as standards for validation were established using a structured psychiatric interview, the SCID, translated for use in Brazilian context. ${ }^{28,29}$

\section{Feasibility Assessment}

The community health workers and nurses assistants who administered the SRQ-20, WHO-5, and COOP/ WONCA Charts completed a questionnaire about the feasibility of their use. It had 9 items focused on understanding of the instructions, questions, and answers of each tool; their brevity, ease of use, and suitability for 
administration in routine care; and their contribution to identifying patients who needed help in dealing with emotional difficulties (ie, a questionnaire's clinical relevance). There were 4 response options for each item: unsatisfactory, doubtfully satisfactory, reasonably satisfactory, and fully satisfactory. ${ }^{39,40}$

\section{Participants}

The study was approved by the Research Ethics Committee of the University Community Health Center of the University of Sao Paulo, and each patient and team member gave written consent to participate. The patients included had no previous interaction with the consultant psychiatrist (either through personal attendance or case discussion). The patients registered with teams were similar to the general population in terms of the sex ratio (with about $50 \%$ of each sex) and age (with about 50\% aged between 20 and 39 years).

We selected a sample size of 120 patients based on a mathematic model for sample size calculation for studies assessing the sensitivity and specificity of diagnostic tests. ${ }^{41}$ Based on previous studies of prevalence of mental disorders and validity of screens for them in Brazilian primary health care, ${ }^{8,35}$ we considered the following expected parameters: a sensitivity of $85 \%$; a specificity of $80 \%$; a $95 \%$ confidence interval of $10 \%$ for sensitivity and specificity; and a prevalence of $40 \%$ of mental disorders in general. To achieve this sample size, a total of 168 patients were invited, of whom 21 did not participate because they had been previously personally assessed by the consultant psychiatrist or involved in the consultation/liaison discussions, 20 because they declined (the main reason given was lack of time), and 7 because they did not complete the psychiatric interview.

\section{Data Collection}

We trained the community health workers and nurse assistants in how to administer the 3 questionnaires in meetings lasting 2 hours with the consultant psychiatrist. The meetings also included discussion of the impact that psychological distress and mental disorders have on patients' lives and how to facilitate patients' communication of such difficulties. The training consisted of reading and dramatization of applications.

At random intervals (on average, once weekly), a researcher visited primary care facilities and invited 1 or 2 patients who were waiting to participate in the study. When patients agreed to participate, community health workers and nurse assistants administered the SRQ-20, the WHO-5, and the COOP/WONCA Charts in a random order during the routine care of these patients. Within a week, a psychiatrist who was trained in the use of the $\mathrm{SCID}^{42-44}$ and had participated in previous studies in which it was used administered the interview in person, remaining blinded to the patients' results on the previous questionnaires. Patients who were determined to have a mental disorder received adequate care in the primary care facilities.

By the end of data collection, 14 community health workers and nurse assistants had administered the screening questionnaires 4 to 9 times each and had completed the questionnaire about feasibility.

\section{Statistical Analysis}

Statistical analyses were performed using the Statistical Package for Social Sciences (SPSS) version 13.0 (SPSS Inc, Chicago, Illinois). To evaluate the predictive validity of the screening questionnaires, considering the presence or absence of psychiatric disorders as measured by the SCID as the reference standard, we generated a receiver operating characteristic (ROC) curve for each questionnaire and calculated its sensitivity, specificity, positive and negative predictive values, and total accuracy. An area under the curve (AUC) of 1.0 was considered to indicate perfect discrimination; an AUC of at least 0.8 , good discrimination; and an AUC of less than 0.7, poor discrimination. ${ }^{45,46}$ The 4 response options for each item of the feasibility questionnaire were grouped into 2 categories, satisfactory (combining reasonably satisfactory and fully satisfactory) and unsatisfactory (combining unsatisfactory and doubtfully satisfactory), and evaluated using absolute numbers and percentages.

\section{RESULTS}

The demographic and clinical characteristics of our patient sample are presented in Table 1. Overall, $36.7 \%$ of patients had at least 1 mental disorder, and depressive and anxiety disorders were most prevalent. Regarding specific diagnoses, the most common were major depressive episode (15.8\% of the sample), generalized anxiety disorder (10\%), panic disorder (4.2\%), and dysthymia (3.3\%). A substantial proportion of patients $(7.5 \%$ of the sample) had comorbid depressive and anxiety disorders

The AUCs for the SRQ-20, the WHO-5, and various COOP/WONCA Charts measures - the total score, the Feelings item, the Daily Activities item, and a 3 -item combination of Feelings, Daily Activities, and Social Activities - indicated that these measures had good discrimination (AUC $\geq 0.8)^{46}$ for any mental disorder and for depressive disorder (Table 2). The COOP/ WONCA Charts total score and the 3 -item combination also had good discrimination for anxiety disorders.

With regard to the diagnosis of any mental disorder by the SCID, the accuracy of the SRQ-20, the WHO-5, and the COOP/WONCA (the total score, 


\begin{tabular}{|c|c|}
\hline Characteristic & No. (\%) \\
\hline \multicolumn{2}{|l|}{ Sex } \\
\hline Women & $62(51.7)$ \\
\hline Men & $58(48.3)$ \\
\hline \multicolumn{2}{|l|}{ Age, y } \\
\hline 15-19 & $18(15.0)$ \\
\hline $20-39$ & $58(48.3)$ \\
\hline $40-49$ & $21(17.5)$ \\
\hline $50-59$ & $12(10.0)$ \\
\hline$\geq 60$ & $11(9.2)$ \\
\hline \multicolumn{2}{|l|}{ Marital status } \\
\hline Cohabiting & $57(47.5)$ \\
\hline Single/divorced/widowed & $63(52.5)$ \\
\hline \multicolumn{2}{|l|}{ Education } \\
\hline Incomplete junior school & $30(25.0)$ \\
\hline Complete junior school & $28(23.3)$ \\
\hline Incomplete or complete high school & $51(42.5)$ \\
\hline Incomplete or complete bachelor degree/more & $11(9.2)$ \\
\hline \multicolumn{2}{|l|}{ No. of SCID diagnoses } \\
\hline 0 & $76(63.3)$ \\
\hline 1 & $25(20.8)$ \\
\hline 2 & $11(9.2)$ \\
\hline 3 & $8(6.7)$ \\
\hline \multicolumn{2}{|l|}{ SCID diagnostic category } \\
\hline Depressive disorders & $25(20.8)$ \\
\hline Anxiety disorders & $21(17.5)$ \\
\hline Substance abuse/dependence & $7(5.8)$ \\
\hline Somatoform disorders & $5(4.2)$ \\
\hline Eating disorders & $3(2.5)$ \\
\hline Adjustment disorders & $3(2.5)$ \\
\hline Psychotic disorders & $1(0.8)$ \\
\hline
\end{tabular}

SCID = Structured Clinical Interview for the Diagnostic and Statistical Manual of Mental Disorders, Fourth Edition. the 3 -item combination, and the single item Feelings) were high and similar, with values ranging from 0.85 to 0.87 (Table 3).

Almost all community health workers and nurse assistants (71.4\%-100\%) rated the understandability, ease of use, and clinical relevance of the SRQ-20, WHO-5, and COOP/WONCA Charts as satisfactory. When it came to brevity, most community health workers and nurse assistants considered these questionnaires to be unsatisfactory for use at every appointment for each patient (100\% for SRQ-20, $71.4 \%$ for WHO-5, and $64.3 \%$ for COOP/WONCA), but suitable for use every 6 months for each patient (100\% for each questionnaire).

\section{DISCUSSION}

We found a $36.7 \%$ prevalence of mental disorders in our study population, which agrees with the relatively high rates of these disorders in Brazilian primary care facilities found in other studies. ${ }^{35,47}$ Additionally, our moderate to good results obtained using the SRQ-20 and WHO-5 to screen for general mental disorders and for depression, respectively, are in accordance with results of previous studies conducted with primary care patients in other countries. ${ }^{48-52}$

The main findings of this study are the good psychometric characteristics of the COOP/WONCA Charts, when administered by community health workers and nurse assistants after a training program conducted within a collaborative care model, to screen both for mental disorders generally and for specific ones present in primary care. Previous studies com-

Table 2. Area Under the ROC Curve (95\% Confidence Interval) for the Questionnaires Studied ${ }^{a}$

\begin{tabular}{|c|c|c|c|c|}
\hline Questionnaire & $\begin{array}{l}\text { Any Mental } \\
\text { Disorder }\end{array}$ & $\begin{array}{l}\text { Depressive } \\
\text { Disorders }\end{array}$ & $\begin{array}{l}\text { Anxiety } \\
\text { Disorders }\end{array}$ & $\begin{array}{l}\text { Substance Abusel } \\
\text { Dependence }\end{array}$ \\
\hline SRQ-20 & $0.93(0.87-0.97)$ & $0.86(0.79-0.93)$ & $0.78(0.70-0.87)$ & $0.72(0.60-0.84)$ \\
\hline WHO-5 & $0.90(0.85-0.96)$ & $0.83(0.75-0.91)$ & $0.76(0.66-0.86)$ & $0.67(0.52-0.81)$ \\
\hline COOPIWONCA Charts ${ }^{b}$ & $0.89(0.82-0.95)$ & $0.81(0.73-0.90)$ & $0.82(0.74-0.91)$ & $0.76(0.51-0.96)$ \\
\hline \multicolumn{5}{|l|}{ Charts item } \\
\hline Feelings & $0.88(0.81-0.94)$ & 0.80 (0.71-0.89) & $0.79(0.70-0.89)$ & $0.74(0.62-0.85)$ \\
\hline Daily Activities & $0.80(0.72-0.88)$ & $0.80(0.72-0.88)$ & $0.70(0.59-0.81)$ & $0.73(0.54-0.92)$ \\
\hline Overall Health & $0.79(0.71-0.86)$ & $0.75(0.65-0.85)$ & $0.80(0.70-0.90)$ & $0.73(0.35-0.77)$ \\
\hline Social Activities & $0.78(0.70-0.87)$ & $0.72(0.61-0.84)$ & $0.81(0.71-0.90)$ & $0.77(0.58-0.96)$ \\
\hline Physical Fitness & $0.63(0.53-0.73)$ & $0.58(0.46-0.70)$ & $0.57(0.44-0.70)$ & $0.63(0.38-0.88)$ \\
\hline Change in Health & $0.54(0.43-0.65)$ & $0.49(0.35-0.63)$ & $0.50(0.36-0.65)$ & $0.56(0.31-0.81)$ \\
\hline Charts 3-item combination & $0.91(0.85-0.96)$ & $0.84(0.77-0.92)$ & $0.82(0.74-0.91)$ & $0.79(0.63-0.96)$ \\
\hline \multicolumn{5}{|c|}{$\begin{array}{l}\text { COOP/WONCA = Dartmouth Primary Care Cooperative Research Network, and World Organization of National Colleges, Academies, and Academic Associations of } \\
\text { General Practitioners/Family Physicians; ROC = receiver operating characteristic; SRQ-20 = } 20 \text {-item Self-Reporting Questionnaire; WHO-5 = World Health Organization } \\
\text { Five Well-Being Index. }\end{array}$} \\
\hline \multicolumn{5}{|c|}{$\begin{array}{l}\text { a Reference standard was diagnosis of the disorders by SCID, the Structured Clinical Interview for the DSM-IV (Diagnostic and Statistical Manual of Mental Disorders, Fou } \\
\text { Edition). }\end{array}$} \\
\hline
\end{tabular}




\begin{tabular}{|c|c|c|c|c|c|c|}
\hline Questionnaire & $\begin{array}{l}\text { Cutoff } \\
\text { Score }\end{array}$ & $\begin{array}{l}\text { Total } \\
\text { Accuracy }\end{array}$ & Sensitivity & Specificity & PPV & NPV \\
\hline SRQ-20 & 8 & 0.85 & 0.81 & 0.86 & 0.78 & 0.89 \\
\hline WHO-5 & 11 & 0.85 & 0.77 & 0.89 & 0.81 & 0.87 \\
\hline $\begin{array}{l}\text { COOP/WONCA } \\
\text { Charts }^{\circ}\end{array}$ & 17 & 0.87 & 0.84 & 0.88 & 0.80 & 0.91 \\
\hline \multicolumn{7}{|l|}{ Charts item } \\
\hline Feelings & 3 & 0.85 & 0.84 & 0.86 & 0.77 & 0.90 \\
\hline Daily Activities & 2 & 0.74 & 0.91 & 0.64 & 0.60 & 0.92 \\
\hline Social Activities & 3 & 0.76 & 0.59 & 0.86 & 0.70 & 0.78 \\
\hline Overall Health & 5 & 0.72 & 0.64 & 0.82 & 0.67 & 0.80 \\
\hline $\begin{array}{l}\text { Charts 3-item } \\
\text { combination }\end{array}$ & 9 & 0.87 & 0.86 & 0.88 & 0.81 & 0.92 \\
\hline \multicolumn{7}{|c|}{$\begin{array}{l}\text { COOP/WONCA = Dartmouth Primary Care Cooperative Research Network, and World Organization of National } \\
\text { Colleges, Academies, and Academic Associations of General Practitioners/Family Physicians; NPV = negative } \\
\text { predictive value; PPV = positive predictive value; ROC = receiver operating characteristic; SRQ-20 = 20-item } \\
\text { Self-Reporting Questionnaire; WHO-5 = World Health Organization-Five Well-Being Index. }\end{array}$} \\
\hline \multicolumn{7}{|c|}{$\begin{array}{l}\text { a Reference standard was diagnosis of the disorders by SCID, the Structured Clinical Interview for the DSM-IV } \\
\text { (Diagnostic and Statistical Manual of Mental Disorders, Fourth Edition). }\end{array}$} \\
\hline \multicolumn{7}{|c|}{${ }^{b}$ Cutoff scores were chosen based on the scores having the highest total accuracy. } \\
\hline \multicolumn{7}{|c|}{ 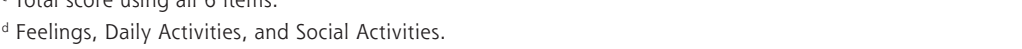 } \\
\hline
\end{tabular}

paring the Feelings item from the COOP/WONCA Charts with a diagnosis of depression made by general practitioners or rating scales of depressive symptoms showed significant concordance. ${ }^{25-27}$ This association had previously not been studied using a structured psychiatric interview administered by an expert or considering diagnoses other than depression, however.

The COOP/WONCA Charts are recommended for routine use by WONCA to monitor the health status of and to facilitate bonding with the patient. ${ }^{23,37}$ This questionnaire is friendly, brief, and easily understood, and can be administered and scored by all team members (or, alternately, can be self-administered). These features, coupled with the results on validity and feasibility as a screen for mental disorders, suggest this it is a good option to accomplish screening in this setting, considering the competing demands and time constraints of primary care services. ${ }^{53,54}$ Routine use of the COOP/WONCA Charts by community health workers and nurse assistants in primary care facilities could thus identify patients who may have mental disorders who could be further evaluated by more detailed interviews, enabling appropriate care sooner. Another important finding is that the Feelings item of the COOP/WONCA Charts has good validity in screening for depression and for mental disorders in general. With respect to depression, some studies have similarly found good results, ${ }^{55-58}$ although a recent meta-analysis considering all studies of the issue does not recommend the use of just a single question to detect depression. ${ }^{59}$ Yet, an earlier study found that a single question of the 5 -item Mental Health Inventory (MHI5) can have a moderate validity for tracking mental disorders in general in primary care. ${ }^{55}$ Regardless, we observed the best psychometric characteristics in the present study with combination of 3 items of the COOP/ WONCA Charts (Feelings, Daily Activities, and Social Activities).

This study has its limitations. Some diagnoses (eg, posttraumatic stress disorder and bipolar disorder) were absent or rare in our sample and could not be evaluated. Only 1 psychiatrist administered the SCID, and that professional was the same one who trained the community health workers and nurse assistants. The psychiatrist was blinded to the diagnoses obtained with the questionnaires until the end of the data collection phase, however. Hence, it is unlikely that the expectation of a good result from the training affected the results. It is also possible that diagnostic errors occurred systematically in application of the SCID, but such errors are also unlikely because the professional's initial SCID training involved group interviews, with other specialized professionals, with appropriate interrater reliability ${ }^{43,44}$ It is also questionable as to whether the study's results can be generalized to staff who do not work in collaborative care programs and do not have consultation/liaison psychiatrists and specific training in the questionnaires studied.

In conclusion, we found that the COOP/WONCA Charts are a useful instrument to screen for mental disorders with good psychometric qualities in a real-world setting when administered by community health workers and nurse assistants. This finding presupposes that training in their use is incorporated into multifaceted learning strategies and that use occurs in the context of a collaborative care model having both mental health specialists and primary care teams. Future studies should examine the impact of using this questionnaire among patients with mental disorders treated in primary care, including its use in conjunction with structured diagnostic interviews conducted by physicians and nurses in primary care to diagnose specific mental disorders ${ }^{42}$ and as an instrument to assess the outcome of treatments for these disorders.

To read or post commentaries in response to this article, see it online at http://www.annfammed.org/cgi/content/full/9/4/359. 
Key words: Mental disorders; depressive disorders; anxiety disorders; screening; primary health care; collaborative care; COOP/WONCA Charts; SCID

Submitted November 3, 2010; submitted, revised, February 26, 2011; accepted March 15, 2011.

Funding support: This study was supported by a grant from "Conselho Nacional de Desenvolvimento Científico e Tecnológico" ("CNPq"), Brazil, number 575094/2008-7. A.W.Z is recipient of a productivity fellowship (CNPq, Brazil)

\section{References}

1. Kessler RC, Aguilar-Gaxiola S, Alonso J, et al. The global burden of mental disorders: an update from the WHO World Mental Health (WMH) surveys. Epidemiol Psichiatr Soc. 2009;18(1):23-33.

2. Vazquez-Barquero JL, Herran A, Simon JA. Epidemiology of mental disorders in the community and primary care. In: Tansella M, Thornicroft G, eds. Common Mental Disorders in Primary Care. London, United Kingdom: Routledge; 1999:3-16.

3. Almeida-Filho N, Mari Jde J, Coutinho E, et al. Brazilian multicentric study of psychiatric morbidity. Methodological features and prevalence estimates. Br J Psychiatry. 1997;171:524-529.

4. Druss BG, Hwang I, Petukhova M, Sampson NA, Wang PS, Kessler RC. Impairment in role functioning in mental and chronic medical disorders in the United States: results from the National Comorbidity Survey Replication. Mol Psychiatry. 2009;14(7):728-737.

5. Eaton WW, Martins SS, Nestadt G, Bienvenu OJ, Clarke D, Alexandre P. The burden of mental disorders. Epidemiol Rev. 2008;30:1-14.

6. Scott KM, Von Korff M, Alonso J, et al. Mental-physical co-morbidity and its relationship with disability: results from the World Mental Health Surveys. Psychol Med. 2009;39(1):33-43.

7. Patten SB, Williams JV, Lavorato DH, Modgill G, Jetté N, Eliasziw M. Major depression as a risk factor for chronic disease incidence: longitudinal analyses in a general population cohort. Gen Hosp Psychiatry. 2008;30(5):407-413.

8. Villano LAB, Nanhay ALG, De Moraes LR, Costa e Silva JA. Results from the Rio de Janeiro Centre. In: Ustun TB, Sartorius N, eds. Mental Illness in General Health Care: An International Study. Chichester, United Kingdom: John Wiley \& Sons Ltd; 1995:371-376.

9. Goldberg D, Mann A, Tylee A. Primary care. In: Thornicroft G, Szmukler G, eds. Textbook of Community Psychiatry. Avon, United Kingdom: Oxford University Press; 2001:409-416.

10. Fernández A, Haro JM, Martinez-Alonso M, et al. Treatment adequacy for anxiety and depressive disorders in six European countries. Br J Psychiatry. 2007;190:172-173.

11. Kates N. Shared mental health care. The way ahead. Can Fam Physician. 2002;48:853-855, 859-861.

12. Bower P, Gilbody S, Richards D, Fletcher J, Sutton A. Collaborative care for depression in primary care. Making sense of a complex intervention: systematic review and meta-regression. Br J Psychiatry. 2006;189:484-493

13. Unützer J, Schoenbaum M, Druss BG, Katon WJ. Transforming mental health care at the interface with general medicine: report for the presidents commission. Psychiatr Serv. 2006;57(1):37-47.

14. World Health Organization (WHO). Integrating Mental Health in Primary Care: A Global Perspective. Geneva, Switzerland: WHO and World Organization of Family Doctors (WONCA); 2008.

15. Foy R, Hempel S, Rubenstein L, et al. Meta-analysis: effect of interactive communication between collaborating primary care physicians and specialists. Ann Intern Med. 2010;152(4):247-258.
16. Pignone MP, Gaynes BN, Rushton JL, et al. Screening for depression in adults: a summary of the evidence for the U.S. Preventive Services Task Force. Ann Intern Med. 2002;136(10):765-776.

17. Spitzer RL, Williams JBW, Kroenke K, et al. Utility of a new procedure for diagnosing mental disorders in primary care. The PRIMEMD 1000 study. JAMA. 1994;272(22):1749-1756.

18. Gilbody S, Sheldon T, House A. Screening and case-finding instruments for depression: a meta-analysis. CMAJ. 2008;178(8):997-1003.

19. Beusemberg M, Orley JA. User's Guide to the Self Reporting Questionnaire (SRQ). Geneva, Switzerland: Division of Mental Health/World Health Organization; 1994.

20. Goldberg DP, Gater R, Sartorius N, et al. The validity of two versions of the GHQ in the WHO study of mental illness in general health care. Psychol Med. 1997;27(1):191-197.

21. World Health Organization. Info Package: Mastering Depression in Primary Care. Frederiksborg, Denmark: World Health Organization, Regional Office for Europe, Psychiatric Research Unit; 1998.

22. Weissman MM, Broadhead WE, Olfson M, et al. A diagnostic aid for detecting multiple mental disorders. In: Jenkins R, Ustun TB, eds. Preventing Mental Illness: Mental Health Promotion in Primary Care. Chichester, England: John Wiley \& Sons Ltd; 1998:301-312.

23. van Weel C, Konig-Zahn C, Touw-Otten FWMM, van Duijn NP. Meyboom-de Jong B. Measuring Functional Health Status With the COOP/WONCA Charts. A Manual. Groningen, The Netherlands: WONCA, ERGHO, and NCH-University of Groningen; 1995.

24. Heun R, Burkart M, Maier W, Bech P. Internal and external validity of the WHO Well-Being Scale in the elderly general population. Acta Psychiatr Scand. 1999;99(3):171-178.

25. Froom J, Schlager DS, Steneker $S$, Jaffe A. Detection of major depressive disorder in primary care patients. J Am Board Fam Pract. 1993;6(1):5-11.

26. Doetch TM, Alger BH, Glasser M, Levenstein J. Detecting depression in elderly outpatients: findings from depression symptom scales and the Dartmouth COOP charts. Fam Med. 1994;26(8):519-523.

27. Pedersen JK, Damsbo N, Kragstrup J. A screening test for depression in general practice. The COOP/WONCA chart. Ugeskr Laeger. 1999;161(6):787-790.

28. First MB, Spitzer RL, Gibbon M, Williams JBW. Structured Clinical Interview For DSM-IV Axis I Disorders-Clinical Version (SCID-CV). Washington, DC: American Psychiatric Press; 1997.

29. Del-Ben CM, Vilela JAA, Crippa JAS, Hallak JEC, Labate CM, Zuardi AW. Reliability of the Structured Clinical Interview for DSMIVClinical Version translated into Portuguese. Rev Bras Psiquiatr. 2001; 23(3):156-159.

30. da Saude M. Secretaria de Politicas de Saude. Departamento de Atencao Basica: Programa de Saude da Familia [Family Health Program]. Rev Saude Publica. 2000;34(3):316-319.

31. Rasella D, Aquino R, Barreto ML. Impact of the Family Health Program on the quality of vital information and reduction of child unattended deaths in Brazil: an ecological longitudinal study. BMC Public Health. 2010;10:380.

32. Forster AC, Passos AD, Dal-Fabbro AL, Laprega MR. Transformation and trends in preventive and social medicine education at the undergraduate level in a Brazilian medical school. Gac Sanit. 2001;15(6):519-522

33. Forster AC, Laprega MR, Dal-Fabbro AL, et al. Methodology of learning in primary care and family medicine. Aten Primaria. 2002; 30(2):125-129.

34. Stewart M, Brown JB, Weston WW, McWhinney IR, McWilliam CL, Freeman TR. Patient-Centered Medicine: Transforming the Clinical Method. 2nd ed. Abingdon, United Kingdom: Radcliffe Medical Press; 2003

35. Mari JJ, Williams P. A validity study of a psychiatric screening questionnaire (SRQ-20) in primary care in the city of Sao Paulo. Br J Psychiatry. 1986;148:23-26. 
36. Bonsignore M, Barkow $K$, Jessen $F$, Heun R. Validity of the five-item WHO Well-Being Index (WHO-5) in an elderly population. Eur Arch Psychiatry Clin Neurosci. 2001;251(Suppl 2):II27-II31.

37. Bentsen BG, Natvig B, Winnem M. Questions you didn't ask? COOP/WONCA Charts in clinical work and research. World Organization of Colleges, Academies and Academic Associations of General Practitioners/Family Physicists. Fam Pract. 1999;16(2):190-195.

38. Westbury RC, Rogers TB, Briggs TE, et al. A multinational study of the factorial structure and other characteristics of the Dartmouth COOP Functional Health Assessment Charts/WONCA. Fam Pract. 1997;14(6):478-485.

39. Slade M, Thornicroft G, Glover G. The feasibility of routine outcome measures in mental health. Soc Psychiatry Psychiatr Epidemiol. 1999;34(5):243-249.

40. Salvador-Carulla L, Salas D. Assessment instruments in psychiatry: description and psychometric properties. In: Tansella M, Thornicroft G, eds. Mental Health Outcome Measures. 2nd ed. London, United Kingdom: Gaskell; 2001:228-257.

41. Buderer NM. Statistical methodology: I. Incorporating the prevalence of disease into the sample size calculation for sensitivity and specificity. Acad Emerg Med. 1996;3(9):895-900.

42. de Azevedo Marques JM, Zuardi AW. Validity and applicability of the Mini International Neuropsychiatric Interview administered by family medicine residents in primary health care in Brazil. Gen Hosp Psychiatry. 2008;30(4):303-310.

43. Del-Ben CM, Rodrigues CRC, Zuardi AW. Reliability of the Portuguese version of the structured clinical interview for DSM-III-R (SCID) in a Brazilian sample of psychiatric outpatients. Braz J Med Biol Res. 1996;29(12):1675-1682.

44. Rufino AC, Uchida RR, Vilela JA, Marques JM, Zuardi AW, Del-Ben CM. Stability of the diagnosis of first-episode psychosis made in an emergency setting. Gen Hosp Psychiatry. 2005;27(3):189-193.

45. Zou KH, Tuncali K, Silverman SG. Correlation and simple linear regression. Radiology. 2003;227(3):617-622.

46. Hanley JA, McNeil BJ. The meaning and use of the area under a receiver operating characteristic (ROC) curve. Radiology. 1982;143 (1):29-36.

47. Mari Jde J, lacoponi E, Williams P, Simões O, Silva JB. Detection of psychiatric morbidity in the primary medical care setting in Brazil. Rev Saude Publica. 1987;21(6):501-507.
48. Abas M, Baingana F, Broadhead J, Iacoponi E, Vanderpyl J. Common mental disorders and primary health care: current practice in low-income countries. Harv Rev Psychiatry. 2003;11(3):166-173.

49. Harpham T, Reichenheim M, Oser R, et al. Measuring mental health in a cost-effective manner. Health Policy Plan. 2003;18(3):344-349.

50. Saipanish R, Lotrakul M, Sumrithe S. Reliability and validity of the Thai version of the WHO-Five Well-Being Index in primary care patients. Psychiatry Clin Neurosci. 2009;63(2):141-146.

51. Mergl R, Seidscheck I, Allgaier AK, Möller HJ, Hegerl U, Henkel V. Depressive, anxiety, and somatoform disorders in primary care: prevalence and recognition. Depress Anxiety. 2007;24(3):185-195.

52. Henkel V, Mergl R, Kohnen R, Maier W, Möller HJ, Hegerl U. Identifying depression in primary care: a comparison of different methods in a prospective cohort study. BMJ. 2003;326(7382):200-201.

53. Wasson J, Keller A, Rubenstein L, Hays R, Nelson E, Johnson D. Benefits and obstacles of health status assessment in ambulatory settings. The clinician's point of view. The Dartmouth Primary Care COOP Project. Med Care. 1992;30(5 Suppl):MS42-MS49.

54. Mitchell AJ. Why do clinicians have difficulty detecting depression? In: Mitchell AJ, Coyne JC, eds. Screening for Depression in Clinical Practice: An Evidence-Based Guide. New York, NY: Oxford University Press; 2010:57-82

55. Berwick DM, Murphy JM, Goldman PA, Ware JE Jr, Barsky AJ, Wein stein MC. Performance of a five-item mental health screening test. Med Care. 1991;29(2):169-176

56. Williams JW Jr, Mulrow CD, Kroenke K, et al. Case-finding for depression in primary care: a randomized trial. Am J Med. 1999; 106(1):36-43

57. Means-Christensen AJ, Arnau RC, Tonidandel AM, Bramson R, Meagher MW. An efficient method of identifying major depression and panic disorder in primary care. J Behav Med. 2005;28(6):565-572.

58. Ayalon L, Goldfracht M, Bech P. 'Do you think you suffer from depression?' Reevaluating the use of a single item question for the screening of depression in older primary care patients. Int J Geriatr Psychiatry. 2010;25(5):497-502.

59. Mitchell AJ, Coyne JC. Do ultra-short screening instruments accurately detect depression in primary care? A pooled analysis and meta-analysis of 22 studies. Br J Gen Pract. 2007;57(535):144-151. 